\title{
PEMANFAATAN HISTORY PADA BROWSERKOMPUTER UNTUK MENENTUKAN PEMILIHAN WEBSITE ATAU BLOG PADA SEOINDONESIA
}

\author{
Ketut Agus Adi Arlina, Yenni Astuti \\ Jurusan Teknik Informatika \\ Sekolah Tinggi Teknologi Adisutjipto Yogyakarta \\ informatika@stta.ac.id
}

\begin{abstract}
Seoindonesia is a web based application that is used to boost the ratings visitors of website or blog using Together in Single Connection (TSC) technique. In this software, the selection of blogs or websites that would be raised using a lowest ratings pattern. Website or blogs listed on Seoindonesia opened by random with choosing some websites or blogs that has the lowest ratings. The selection of a websites or blogs randomly, causing discomfort to the user side. One way to access and improve seoindonesia is to use history on the browser. History on the browser is a facility to record and store data of story browsing and use of the internet search history. Utilization history on browser can only be accessed by using the extension. Extensions is a plug-in applications that have a specific function and can be installed on a computer's browser. Web browser noted most frequently visited of history or blog and than sent to the extensions can be used to direct the opening of a new website or blog address in accordance with the categories of the previous website address. Website or a blogsposted by extension, is a member of seoindonesia, so it can increase the number of visitors who will rise the rank, with an increase of $64 \%$ (7 points) and 36\% (4 points) decreased with the overall function of the test is 11 points in seo alexa rank.Application development by using a browser on computer, able to improve the system seoindonesia on the grouping and categorizing of website or blog.
\end{abstract}

Keywords : History of browser, website, seoindonesia

\section{Pendahuluan}

Salah satu cara untuk mengkaji dan memperbaiki Seoindonesia versi Zuliana yaitu dengan History pada browser untuk memilihkan alamat web atau blog yang sudah menjadi anggota Seoindonesia. History di browser adalah fasilitas untuk mencatat dan menyimpan data sejarah penelusuran dan penggunaan internet, history ini bisa sangat bermanfaat jika ingin melihat situs mana saja yang pernah dikunjungi.Dengan adanya history pada browser,dapat menganalisis dan memanfaatkan lebih dari fungsi utamanya sebagai pencatat riwayat penjelajahan pada jaringan internet.Fungsi itu dapat bekerja secara maksimal dengan membuat sebuah ekstensi yang dipasang di browser.Dari analisis itu,mendapatkan data-data yang dapat diolah menjadi informasi-informasi yang lebih berguna contohnya adalah dapat me-record website-website yang sering dikunjungi.Pemilihan website atau blog pada Seoindonesia menggunakan cara yang diuraikan diatas, tingkat keberhasilannya diukur menggunakan situs perankingan alexa. Dari paparan gagasan tersebut, dalam Tugas Akhir ini, penulis mengangkat permasalahan itu dalam judul Pemanfaatan History pada BrowserKomputer untuk menentukan pemilihan website atau blog pada Seoindonesia. 


\section{Kajian Pustaka}

Teknik TSC merupakan teknik yang sudah ada terlebih dahulu, yang dapat digunakan untuk menaikkan ranking blog. Penerapan sistem terdistribusi pada TSC memanfaatkan landing page sebagai perantaranya.Landing page berfungsi sebagai penghubung antara aplikasi web atau blogyang terdaftar sebagai anggota untuk menaikkan ranking dengan database pada aplikasi sisi server. Ketika seseorang melakukan klik terhadap landing page Seoindonesia, akan membuka blog atau web anggota yang lainnya. Sehingga Landing page dapat digunakan sebagai cara untuk menghitung jumlah pengunjung sebuah blog atau website yang pada akhirnya dapat menaikkan 1 kunjungan dan jumlah halaman dengan 1 klik button Seoindonesia pada pengujian histats.com (Zuliana, 2013).

\section{Metodologi Penelitian}

\subsection{Internet dan Browser}

Interconnection network atau yang sering disebut dengan internet adalah sistem global dari seluruh jaringan komputer yang saling terhubung.Internet berasal dari bahasa latin "inter" yang berarti "antara". Internet merupakan jaringan yang terdiri dari milyaran komputer yang ada di seluruh dunia.Internet melibatkan berbagai jenis komputer serta topologi jaringan yang berbeda.Dalam mengatur integrasi dan komunikasi jaringan, digunakan standar protokol internet yaitu TCP/IP.TCP bertugas untuk memastikan bahwa semua hubungan bekerja dengan baik, sedangkan IP bertugas untuk mentransmisikan paket data dari satu komputer ke komputer lainya.

History di browser adalah fasilitas untuk mencatat dan menyimpan data sejarah penelusuran dan penggunaan internet, history ini bisa sangat bermanfaat jika ingin melihat situs mana saja yang pernah kita kunjungi. Fasilitas ini bisa dimanfaatkan untuk melacak kemana saja browser pernah menjelajah, jika komputer juga pernah dipakai oleh orang lain. Manfaat lain dari History ini adalah jika ingin mencari suatu informasi, dan informasi tersebut berada pada situs yang pernah dikunjungi namun lupa alamat dari situs tersebut, dan lupa untuk mem-bookmark situs tersebut. Maka bisa memanfaatkan fasilitas history ini untuk mencari lagi situs tersebut.Fasilitas history pada browser menghemat waktu dan tenaga karena tinggal dipilih website yang ingin dikunjungi ulang yang masih tercatat pada history.

\subsection{Google Chrome}

Google Chrome merupakan browser yang dikeluarkan oleh Google, sebuah perusahaan search engine terkemuka di dunia. Google Chrome juga dirancang agar berjalan secepat mungkin.Cepat dimulai dari desktop, memuat halaman web dalam sekejap, dan menjalankan aplikasi web yang rumit dengan sangat cepat. Chrome pertama kali di rilis oleh Google pada tanggal 2 September 2008, saat itu hanya untuk Microsoft Windows karena masih dalam status beta. Lalu pada 11 Desember di tahun yang sama Google Chrome diluncurkan untuk semua sistem operasi karena telah mencapai versi stabil. Dan pada bulan Januari 2012, Google Chrome diperkirakan telah berhasil meraih presentase $25-28 \%$ dari keseluruhan pengguna browser dunia, membuatnya sebagai browser kedua atau juga ketiga paling banyak di gunakan setelah Mozilla Firefox.

Extentions pada google chrome dapat mengacu kepada ekstensi atau plugin tambahan yang tidak dipasang secara built-in ketika melakukan instalasi baru Google Chrome. Extentions dibangun dengan memiliki fungsi tertentu yang dapat membantu dalam proses penjelajahan 
internet. Seiring berkembangnya kebutuhan, google menawarkan konsep aplikasi web.Extentions tersebut nantinya akan dihosting ke dalam Google web store. Extentions yang sudah terinstal pada browsergoogle chrome terletak berjejer secara instan pada pojok kanan atas Google Chrome.

\subsection{Search Engine Optimization (SEO)}

SEO merupakan sebuah proses yang digunakan untuk mengoptimalkan dan memaksimalkan halaman blog untuk pencarian dalam mesin pencari. Proses tersebut merupakan sebuah teknik pemasaran internet yang ditujukan untuk meningkatkan trafik kunjungan dalam sebuah konten jaringan dan meningkatkan kualitas trafik sendiri. Penerapan SEO ini menggunakan sebuah algoritma yang digunakan pada sebuah mesin pencari.Salah satunya adalah algoritma PageRank.Algoritma ini memperhitungkan jumlah link yang mengarah ke situs tertentu dan jumlah trafik yang dihitung dari halaman itu sendiri dengan halaman yang terdapat link tersebut berada.

\subsection{Analisa dan Perancangan}

\subsubsection{Analisa Sistem}

Analisa dari aplikasi seoindonesia berbasis web ini adalah dengan membukakan blog atau website anggota seoindonesia yang sesuai atau relevan dengan isi konten dari website yang sedang dibuka oleh user. Blog atau website yang terbuka merupakan hasil dari analisis pada history browser yang sering dikunjungi oleh user. Dengan pemanfaatan history browser diharapkan akan lebih bermanfaat dalam tingkat kenyaman dan efektifitas pengunjung yang menggunakan seoindonesia selain dari fungsi-fungsi dasar seoindonesia.Skema sistem pada pengembangan seoindonesia dapat dilihat pada Gambar1.

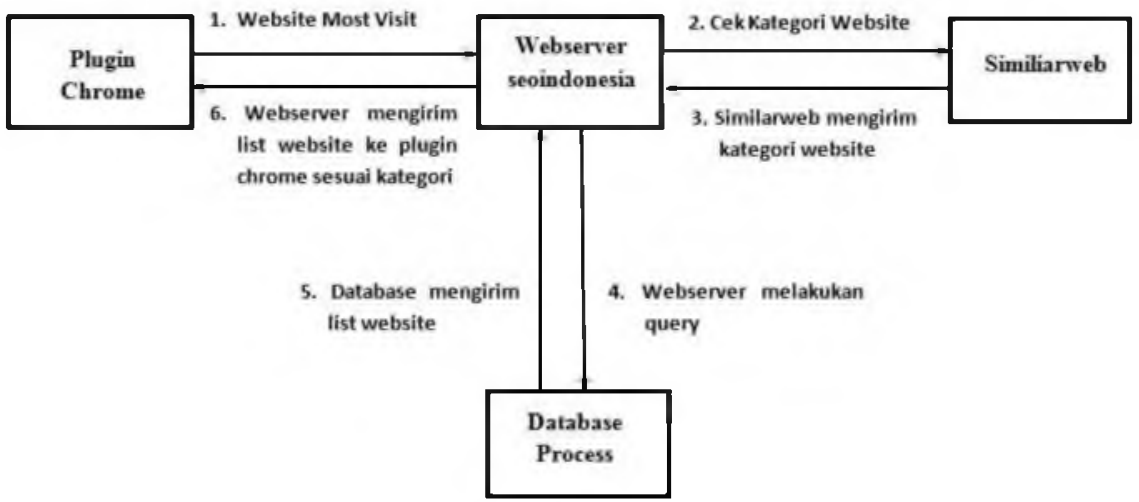

Gambar 1 Skema sistem dari Pengembangan seoindonesia

Gambar skema sistem diatas menjelaskan urutan proses yang terjadi pada seoindoenesia. Untuk lebih rincinya akan dipaparkan sebagai berikut :

1. Plugin atau ekstensi yang dipasang pada browserakan mengirimkan alamat website yang sering dikunjungi oleh userke Webserver seoindonesia dengan menggunakan algoritma tertentu.

2. Alamat-alamat website yang diterima oleh Webserverakan dikirimkan ke webservice similar.com untuk dilakukan pengecekan kategori. Proses ini akan menghasilkan kategori-kategori sesuai dengan isi konten alamat website yang dikirim oleh webserver seoindonesia.

3. Kategori yang dihasilkan webserviceakan dikirim kembali ke webserver seoindonesia. 
4. Hasil kategori ini akan diproses oleh webserver seoindonesia dengan melakukan query pengecekan pada database, apakah ada website yang relevan dengan kategori yang dikirim oleh webservice.

5. Pengecekan yang terjadi pada database Seoindonesia akan menghasilkan nama website atau blog anggota Seoindonesia, yang dikirim kembali ke aplikasi.

6. Hasil query pengecekan akan dikirim ke plugin atau ekstensi untuk bisa ditampilkan kepada user. Hasil query yang diterima plugin atau ekstensiadalah alamat website yang sering dikunjungi yang relevan dengan anggota Seoindonesia.

\subsubsection{Desain Sistem}

Sistem yang akan dibangun pada pengembangan seoindonesia adalah memanfaatkan history pada browser. Historybrowser hanya bisa diakses dengan tiga metode javascript yaitu next() untuk menampilkan website setelahnya, back() untuk menampilkan website sebelumnya dan go() untuk menuju website tertentu. Kebijakan dari browser ini menjadikan kendala untuk mengakses historybrowoser lebih jauh. Solusi yang dapat diambil adalah membuat ekstensi atau plugin yang akan di pasang pada browser Google Chrome. Ekstensi ini berisi algoritma yang bertugas untuk menampilkan blog atau website yang sering dikunjungi oleh user yang relevan atau sesuai dengan blog anggota yang sudah terdaftar di seoindonesia. Selain ekstensi, pengembangan aplikasi seoindonesia juga memanfaatkan webservice yaitu similar.com. Similar.com adalah website yang akan mengkategorikan blog atau website anggota seoindonesia sesuai dengan isi kontennya. Dengan memanfaatkan webservice ini, kita dapat mengetahui termasuk kategori apakah anggota seoindonesia tersebut.

\subsubsection{Diagram Konteks Indonesia}

Diagram konteks adalah diagram yang terdiri dari suatu proses dan menggambarkan ruang lingkup suatu sistem. Diagram konteks merupakan level tertinggi dari DFD yang menggambarkan seluruh input ke sistem atau output dari sistem. Diagram konteks memberikangambaran tentang keseluruan sistem.Secara keseluruhan Seoindonesia memiliki tiga entitas yaitu admin,anggota,danuser. Masing-masing entitas tersebut memiliki hak akses yang berbeda terhadap aplikasi Seoindonesia.Dengan berbedanya hak akses pada entitas, maka aktifitas data yang terjadi pada aplikasi Seoindonesia juga berbeda.Hubungan antara tiga entitas tersebut terhadap Seoindonesia dapat dilihat pada Gambar 2. 


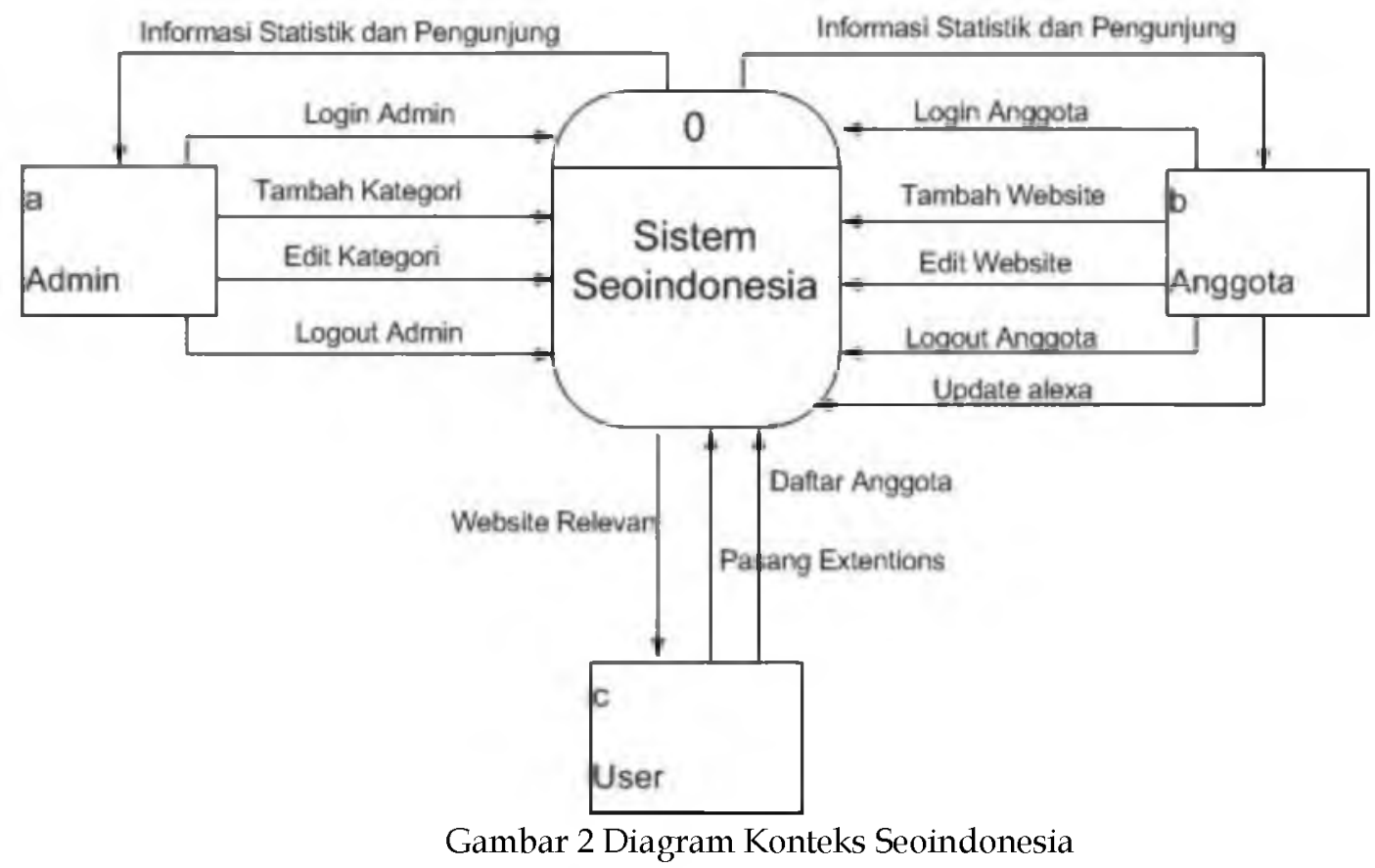

\subsubsection{DAD Level 0 Sistem Seoindonesia}

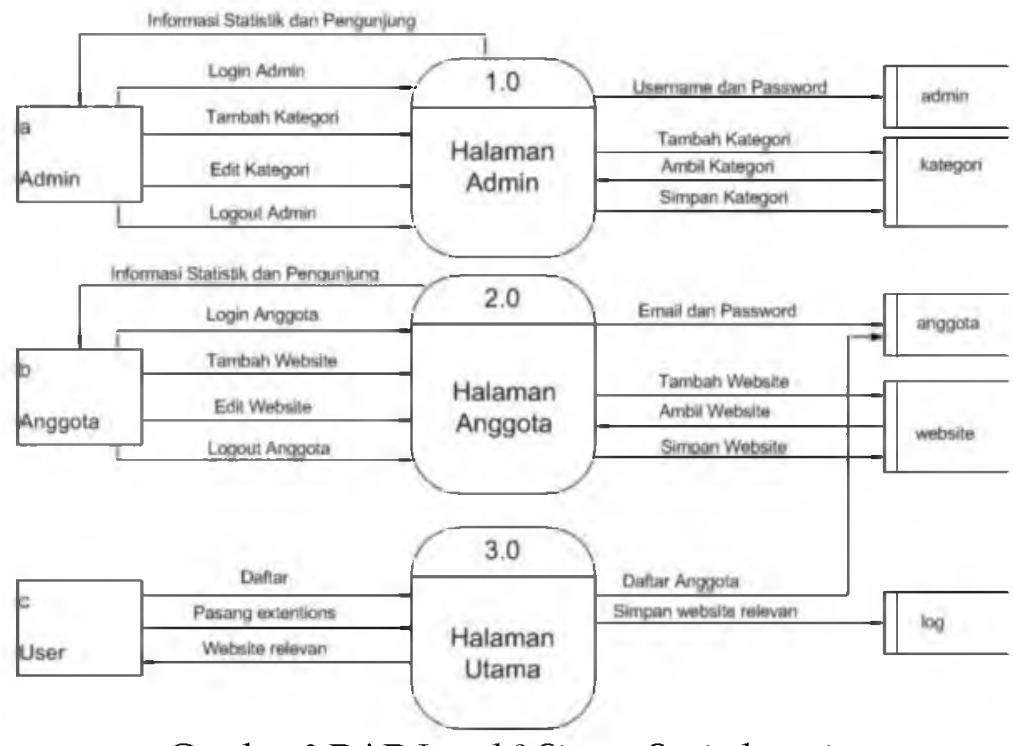

Gambar 3 DAD Level 0 Sistem Seoindonesia

DAD level 0 merupakan tahapan proses yang ada di dalam diagram konteks, yang penjabarannya lebih terperinci. Admin sebagai pengelola sistem harus melakukan proses login terlebih dahulu untuk dapat mengakses halaman admin. Begitu juga seorang anggota melakukan hal yang sama dengan melakukan proses login terlebih dahulu untuk dapat mengakses halaman anggota. User sebagai pengguna secara langsung dapat melakukan proses pemasangan ekstensi ataupun pendaftaran menjadi seorang anggota. DAD level 0 dapat dilihat pada Gambar 3. 


\section{Hasil Dan Pembahasan}

\subsection{Uji Fungsi}

Aplikasi pengembangan dari Seoindonesia, merupakan aplikasi yang membukakan website atau blog tidak secara acak, melainkan dengan cara analisis pada historybrowser untuk mendapatkan web atau blog yang relevan. Fungsi dari ekstensi ini diharapkan mampu memberikan kenyamanan pada dua arah, antara pengguna ekstensi dan anggota yang sudah terdaftar pada sistem aplikasi seoindonesia. Pengguna ekstensi akan mendapatkan alamat website yang sesuai atau relevan dengan history browser-nya. Sedangkan anggota seoindonesia secara otomatis mendapatkan jumlah kunjungan pada website atau blog-nya, sehingga mudah dikenal khalayak ramai.Berikut ini adalah contoh gambar ekstensi saat menghasilkan alamat website atau blog anggota Seoindonesia yang merupakan kategori sesuai dengan alamat yang paling sering dikunjungi atau topsiteyang ada di history browser.

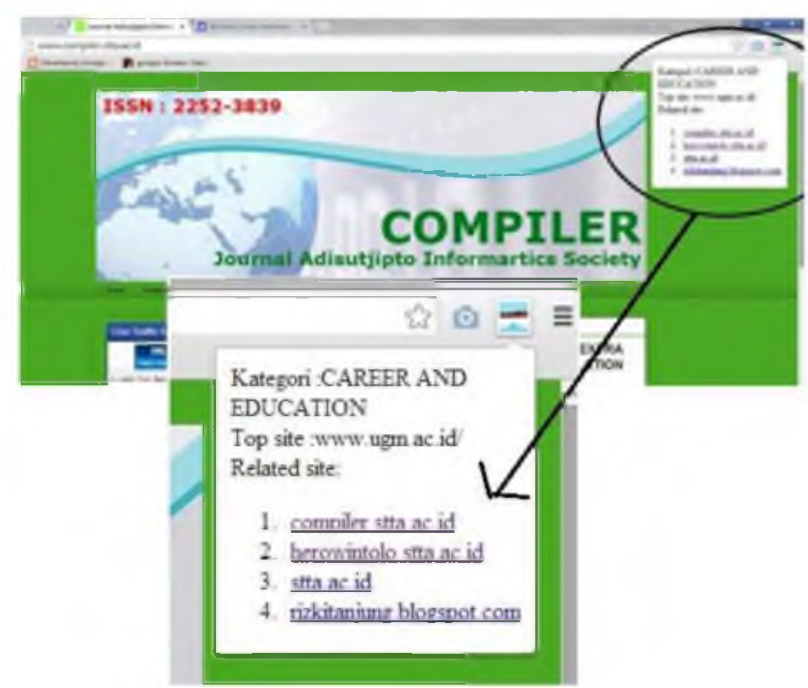

Gambar 4 Ektensi menampilkan alamat kategori Career and Educationdengan topsite wrow.ugm.ac.id

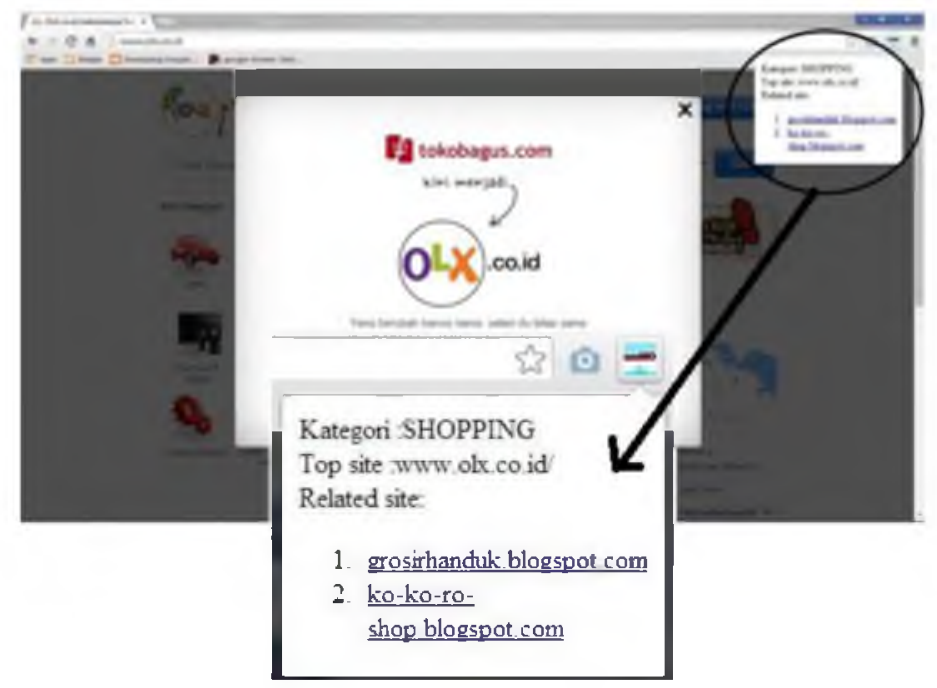

Gambar 5 Ekstensi menampilkan alamat kategori Shopping dengan topsitewww.olx.co.id

\subsection{Pembahasan}

Setelah melakukan pengujian, maka akan terjadi kenaikan jumlah pengunjung. Hal ini terjadi ketika sebuah alamat website atau blog hasil dari fungsi ekstensi diakses, maka alamat 
yang sesuai tersebut tidak langsung dieksekusi melainkan di-redirect atau dialihkan terlebih dahulu kedalam basis data perangkat lunak seoindonesia. Setelah proses redirect berlangsung, maka di basis data sistem perangkat lunak akan tercatat sebagai pengunjung. Setiap satu klik pada ekstensi, maka dalam basis data sistem perangkat lunak seoindonesia akan terjadi penambahan satu jumlah pengunjung. Proses ini dapat dilihat pada Gambar 6.

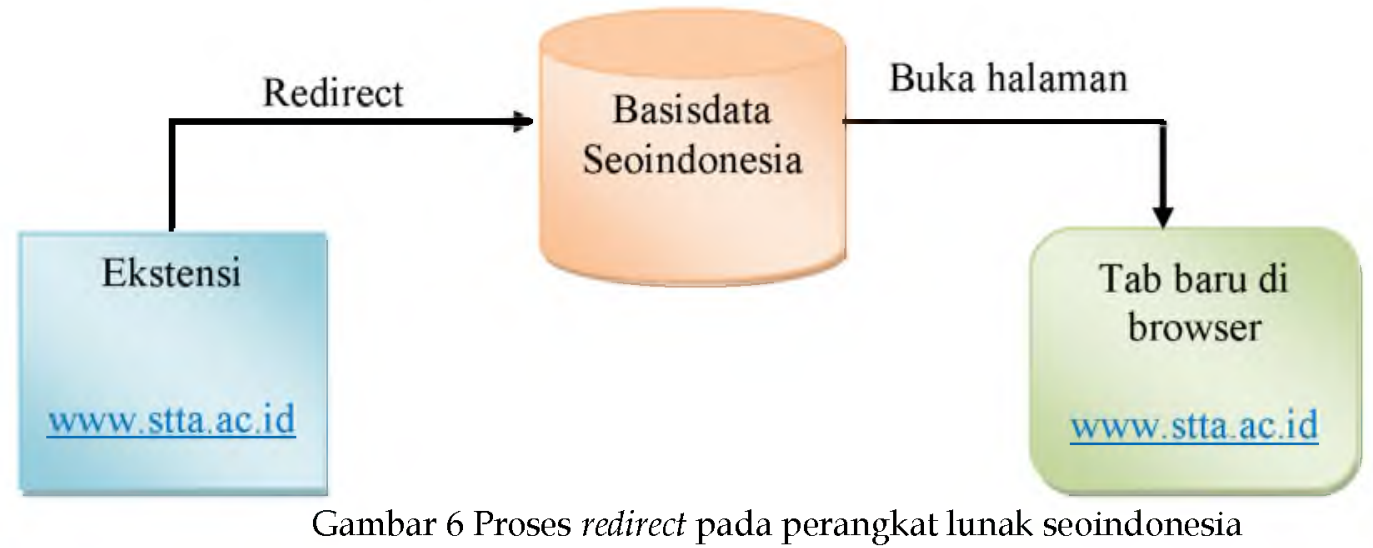

Dalam pengujian ada ranking yang naik dan turun, menurunnya ranking menjadi indikator bahwa semakin kecil ranking dalam alexa maka semakin dikenal website dan blog.Seperti pada Tabel 1 yang menunjukkan perubahan yang terjadi pada ranking seo alexa sebelum dan sesudah pengujian.

Tabel 1 Alamat website atau blog yang diuji fungsi

\begin{tabular}{|l|l|l|l|}
\hline NO & \multicolumn{1}{|c|}{ ALAMAT } & SEBELUM & \multicolumn{1}{c|}{ SESUDAH } \\
\hline 1 & anime-taku-download.blogspot.com & 0 & 0 \\
\hline 2 & ariska138.wordpress.com & 18047261 & 180397026 \\
\hline 3 & bola.net & 1988 & 2009 \\
\hline 4 & bundazaky.wordpress.com & 0 & 0 \\
\hline 5 & blue-evil.blogspot.com & 0 & 0 \\
\hline 6 & candraadiputra.blogspot.com & 9557069 & 1145761 \\
\hline 7 & compiler.stta.ac.id & 2203442 & 2203442 \\
\hline 8 & candra.web.id & 198796 & 198675 \\
\hline 9 & fararainside.net & 6775108 & 5520558 \\
\hline 10 & grosirhanduk.blogspot.com & 17641646 & 17668723 \\
\hline 11 & herowintolo.stta.ac.id & 2203442 & 2072337 \\
\hline 12 & imankutebal.blogspot.com & 0 & 0 \\
\hline 13 & informatikajogja.blogspot.com & 0 & 0 \\
\hline 14 & jati.stta.ac.id & 2203442 & 2072337 \\
\hline 15 & ko-ko-ro-shop.blogspot.com & 0 & 0 \\
\hline 16 & merdeka.com & 1004 & 1002 \\
\hline 17 & ourjunior.wordpress.com & 0 & 0 \\
\hline 18 & p00c4nb4w3l.blogspot.com & 0 & 0 \\
\hline 19 & rizkitanjung.blogspot.com & 0 & 0 \\
\hline 20 & stta.ac.id & 2203442 & 2072337 \\
\hline
\end{tabular}


Perankingan versi alexa ini memiliki kebijakan yang sering berubah-ubah sehingga hasil pengujian yang mendapatkan penurunan ranking versi alexa tidak dapat dijadikan acuan selamanya. Dengan hasil yang didapatkan dalam proses pengujian, maka seoindonesia yang memanfaatkan history dari browsergoogle chrome dapat digunakan untuk mempromosikan website atau blog dan dapat juga untuk menaikkan ranking website tersebut melalui indikator perankingan alexa.

\section{Penutup}

\subsection{Kesimpulan}

Dari hasil uji coba, dapat diambil beberapa kesimpulan sebagai berikut :

1. Perangkat lunak Seoindonesia versi Ketut telah berhasil memperbaiki Seoindonesia versi Zuliana untuk sistem pengelompokan dan pengkategorian website atau blog.

2. History pada browser dapat dimanfaatkan untuk mengarahkan pembukaan alamat website atau blog baru sesuai dengan kategori alamat website sebelumnya.

3. Penggunaan ekstensi pada seoindonesia memberikan pengaruh naiknya jumlah pengunjung website atau blog yang terdaftar sebagai anggota seoindonesia yang berdampak pada meningkatnya ranking dengan mengalami kenaikkan sebesar $64 \%$ (7 point) dan 36\% (4 point) mengalami penurunan dengan uji fungsi keseluruhan yaitu 11 point pada perankingan seo alexa.

\subsection{Saran}

1. Proses pengkategorian yang ada pada seoindonesia supaya lebih spesifik untuk mendapatkan alamat website atau blog yang benar-benar sesuai.

2. Ekstensi supaya dapat di-instalatau dipasang tidak hanya di browser komputer Google Chrome.

3. Sistem aplikasi seoindonesia supaya lebih dipromosikan dan dipublikasikan agar anggotanya semakin banyak.

\section{Daftar Pustaka}

Jogiyanto, HM. 1990, Analisis dan Desain Sistem Informasi.Yogyakarta : Andi Offset

Komputer, Wahana, 2012, Javascript Source Code Paling Dicari!. Andi Offset, Yogyakarta.

Raharjo, Budi.2011, Belajar Otodidak Pemrograman Web Dengan PHP + Oracle, Informatika, Bandung.

Subari, Tata. 2004. Analisa Sistem Informasi. Yogyakarta : Andi Offset

Supriyanto, Aji. 2005. Pengantar Teknologi Informasi. Jakarta : Salemba Infotek

Varghese, Jobi. 2010, Oracle and/or its affiliates.Oracle, Yogyakarta.

Zuliana, 2013,Penerapan Sistem Terdistribusi pada Together in A Single Connection (TSC) Berbasis

Web. Compiler Jurnal Adisutjipto Informartics Society: Volume 2, No 2, Desember 2013.

Jurusan Teknik informatika Sekolah Tinggi Teknologi Adisutjipto, Yogyakarta.

www.stackoverflow.com,diunduh pada hari Sabtu, tanggal 5 Juli 2014, jam 13:00 WIB.

www.w3schools.com/php/default.asp, diunduh pada hari Sabtu, tanggal 12 Juli 2014, jam 09:00 WIB.

wwww.developer.chrome.com/extensions, diunduh pada hari Jumat,tanggal 15 Juli 2014, jam 08:00 WIB. 
www.alexa.com, diunduh pada hari Jumat, tanggal 15 Juli 2014, jam 09:30 wib. www.metroui.org.ua, diunduh pada hari Minggu, tanggal 20 Juli 2014, jam 08:00 WIB.

wwww.developer.similarweb.com/website categorization API, diunduh pada hari Kamis, tanggal 17 Juli 2014, jam 10:00 WIB. 
Ketut Agus Adi Arlina, Yenni Astuti 